Check for updates

Tenterden, Kent

Cite this as: BMJ 2021;373:n1266 http://dx.doi.org/10.1136/bmi.n1266 Published: 17 May 2021

\section{Covid-19: Second vaccine doses expedited in areas of England where new variant is high}

\author{
Jacqui Wise
}

The government has said it was implementing a "belt and braces" approach to tackle rising cases of the B.1.617.2 variant of SARS-CoV-2, though some experts fear that the measures will not be sufficient as lockdown is eased.

Matt Hancock, health and social care secretary for England, told MPs on 17 May that 2323 cases of the variant first identified in India had now been confirmed in the UK. This was up from 1313 on 13 May. ${ }^{1}$ There were now 86 local authorities with five or more cases, he said. Of the new variant cases, 483 have been seen in Bolton and Blackburn with Darwen, where B.1.6.17.2 is now the dominant strain.

Data from the Wellcome Sanger Institute, which excludes samples from recent travellers and surge testing, show that almost $30 \%$ of samples collected in England in the week ending 8 May tested positive for B.1.6.17.2. The variant made up $81.4 \%$ of positive covid-19 tests analysed in Blackburn with Darwen, $81 \%$ in Sefton, $81.4 \%$ in Bolton, and 88\% in Bedford.

The government's measures include bringing forward the appointment for the second dose of the vaccine from 12 to eight weeks after the first dose for the remaining people in the top nine priority groups who haven't yet received their second dose, after advice from the Joint Committee on Vaccination and Immunisation.

In Bolton and Blackburn with Darwen, two areas that have seen a sharp rise in cases of B.1.617.2, there is a push to increase vaccine uptake by boosting delivery of vaccines, extending opening hours at vaccinations centres, opening pop-up sites, and direct engagement with local communities. Additional surge testing with support from the army and increased genome sequencing of positive cases is also occurring in hotspots.

Hancock told MPs that there was a "race between the virus and the vaccine." He said that most of the 18 people in hospital in Bolton with the B.1.617.2 variant had not had the vaccine despite being eligible. He said five people had ended up in hospital after having one jab and one frail patient had received both doses.

In Bolton long queues of people turned up at a mobile vaccination site at the weekend after the Conservative councillor Andy Morgan tweeted that 4000 Pfizer vaccines were available and volunteers would "find a reason to vaccinate you." There were reports that people as young as 17 were getting the vaccine. However, the government is rejecting calls to vaccinate all adults in the most affected areas, saying that surge testing was the best solution.

Bolton Clinical Commissioning Group said that the focus was on eligible groups but urged anyone who vaccination site to check. In February the JCVI announced that factors other than just health and age could be taken into account, so deprivation, ethnicity, and living in a multigenerational household could mean that younger people are eligible for the vaccine.

Lockdown rules eased in England on 17 May, with groups of six people or two households allowed to meet indoors in homes, pubs, cafes, and restaurants for the first time since last autumn. Under the government's roadmap the remaining restrictions are due to be lifted on 21 June.

Hancock said that ministers could again resort to local lockdowns to try to reduce infections in hotspots. But David Greenhalgh, leader of Bolton Council, has called on the government not to "lock us down-do not take us out of the road map." He added, "The majority of our cases are in their teens, 20s, and 30s. Send us more vaccinations and allow us to vaccinate 18 years [and up] now; that is the answer, not further restrictions."

The government's Scientific Advisory Group for Emergencies said it was "highly likely" that the B.1.617.2 variant is more transmissible than the B.1.1.7 variant and "it is a realistic possibility that it is as much as 50\% more transmissible."

In its latest batch of documents SAGE warned that in areas where infection numbers were increasing rapidly an even faster increase could be expected if measures were relaxed. They said that if the variant were to have a 40\%-50\% transmission advantage, progressing with step 3 of the roadmap could lead to a "substantial resurgence of hospitalisations similar to, or larger than, previous peaks." SAGE said there was not yet any clear evidence to show that this variant had a greater effect on severity of disease or evaded the vaccine.

The Independent Scientific Advisory Group for Emergencies also warned, "In light of the new variant, we consider that any increase of mixing in indoor spaces (whether domestic or commercial) to be highly inadvisable, particularly in areas with already proven high levels of B.1.617.2." It has drawn up a six point plan for dealing with the variant, including improved financial and social support for infected people and contacts to self-isolate. ${ }^{3}$

The BMA urged people to be cautious and to meet outdoors wherever possible. Richard Jarvis, co-chair of its public health medicine committee, said, "With key segments of the population still not vaccinated and clusters of variants, including the rapidly increasing Indian variant, becoming a growing was not sure whether they were eligible to get to the 
concern, we must approach this next stage of easing lockdown with the utmost caution.”

Sharon Peacock, director of the Covid-19 Genomics UK Consortium, said, "It is increasingly plausible that B.1.617.2 will go on to replace B.1.1.7 in England over time, in the same way that B.1.1.7 replaced other variants at the end of last year."

She added, “There is no evidence at the moment that vaccines won't work, but we don't know enough yet because most laboratory data generated for this lineage is for B.1.617.1 rather than B.1.617.2-and there are important genetic differences between the two."

The government has been criticised for being too slow to ban flights into the UK from India, which was placed on the red list of high risk countries only on 23 April, two weeks after Pakistan and Bangladesh. The all-party parliamentary group on coronavirus has called for the covid public inquiry to look into this decision and whether it was influenced by politics and not science. The group's chair, the Liberal Democrat MP Layla Moran, said, "It does appear that Boris Johnson put the pursuit of a post-Brexit trade deal with India ahead of public health.”

On 18 May 2021 we amended this article to include new comments from Matt Hancock and additional figures on the prevalence of variant B.1.617.2.

1 Public Health England. SARS-CoV-2 variant data update, England, 13 May 2021. https://assets.publishing.service.gov.uk/government/uploads/system/uploads/attachment_data/file/986316/Variants_of_Concern_Variant_Data_Update_20210512.pdf.

2 Scientific Advisory Group for Emergencies. SAGE 89 minutes: Coronavirus (COVID-19) response, 13 May 2021. https://www.gov.uk/government/publications/sage-89-minutes-coronavirus-covid19-response-13-may-2021.

3 Independent SAGE. Six point plan for dealing with the B.1.617.2 variant. 14 May 2021. https://www.independentsage.org/six-point-plan-for-dealing-with-the-b-1-617-2-variant.

This article is made freely available for use in accordance with BMJ's website terms and conditions for the duration of the covid-19 pandemic or until otherwise determined by BMJ. You may use, download and print the article for any lawful, non-commercial purpose (including text and data mining) provided that all copyright notices and trade marks are retained. 